\title{
Ineffective Esophageal Motility in Patients with GERD is no Contraindication for Nissen Fundoplication
}

\author{
Milena Nikolic $^{1} \cdot$ Katrin Schwameis $^{1} \cdot$ Ivan Kristo $^{1} \cdot$ Matthias Paireder $^{1} \cdot$ Aleksa Matic $^{1}$ • \\ Georg Semmler $^{1} \cdot$ Lorenz Semmler $^{1} \cdot$ Sebastian F. Schoppmann $^{1}{ }^{(1)}$
}

Published online: 11 October 2019

(C) The Author(s) 2019

\begin{abstract}
Background Patients with preoperative ineffective esophageal motility (IEM) are thought to be at increased risk for postoperative dysphagia leading to the recommendations for tailoring or avoiding anti-reflux surgery in these patients. The aim of this study was to evaluate if IEM has an influence on postoperative outcome after laparoscopic Nissen fundoplication (LNF).

Methods Seventy-two consecutive patients with IEM underwent LNF and were case-matched with 72 patients without IEM based on sex, age, BMI, HH size, total pH percentage time, total number of reflux episodes and the presence of BE. Standardized interview assessing postoperative gastrointestinal symptoms, proton pump inhibitor intake, GERD-health-related-quality-of-life (GERD-HRQL), alimentary satisfaction and patients' overall satisfaction was evaluated.

Results Although a higher rate of preoperative dysphagia was observed in patients with IEM (29\% IEM vs. $11 \%$ no IEM, $p=0.007$ ), there was no significant difference in rates of dysphagia postoperatively (2 IEM vs. 1 no IEM, $p=0.559$ ). Furthermore, no distinction was found in the postoperative outcome regarding symptom relief, quality of life, gas bloating syndrome, ability to belch and/or vomit or revision surgery between the two groups.

Conclusion Although preoperative IEM has an influence on GERD presentation, it has no effect on postoperative outcome after LNF. IEM should not be a cause for avoiding LNF, as is has been shown as the most effective and safe anti-reflux treatment.
\end{abstract}

\section{Introduction}

Although the prevalence of GERD has been rising since 1995 , the rates of anti-reflux surgery have, on the contrary, been declining in the last 9 years [1-3]. Reasons for this phenomenon are the feared long-term side effects of persistent dysphagia and gas bloat syndrome [3-6]. The change in trends of GERD and minimal invasive

Sebastian F. Schoppmann

sebastian.schoppmann@meduniwien.ac.at

1 Department of Surgery, Division of General Surgery, Medical University of Vienna, Waehringer Guertel 18-20, 1090 Vienna, Austria innovations in surgery led to more focus on closing the therapy gap between medical and surgical anti-reflux treatment. In an effort to reduce the side-effect rates, while maintaining its efficiency, the gold standard in GERD therapy-the Nissen fundoplication underwent countless modifications, like the partial $270^{\circ}$ Toupet fundoplication (TF) and $120^{\circ}$ Dor fundoplication (DF) [7-9]. As ineffective esophageal motility (IEM) has shown to pose a risk for postoperative dysphagia, TF was preferred in those patients, due to concerns that a total fundoplication could potentially augment the resistance of the normal outflow $[7,8,10,11]$. Although the concept of tailoring anti-reflux surgery in patients with IEM has been adopted nearly two decades ago, numerous studies since have shown that the 
Nissen remains superior to partial fundoplication in longterm reflux cessation and does not increase the dysphagia rates in these patients [12-17]. Furthermore, through restoration of the anti-reflux barrier and improvement of the esophagitis, a correction of the esophageal motor function as well as dysphagia could be accomplished $[16,17]$.

The aim of this study was to analyze the differences in postoperative dysphagia rates, reflux control and degree of overall satisfaction in GERD patients with preoperative diagnosed IEM and those without IEM, who underwent laparoscopic Nissen fundoplication (LNF) in a high-input specialized reflux center.

\section{Materials and methods}

\section{Preoperative assessment}

All patients received a standardized interview, clinical examination, an upper GI endoscopy and esophageal functioning testing consistent of a manometry and a 24-himpedance-pH-metry. GERD was diagnosed by positive $\mathrm{pH}$ results or increased total reflux episodes with positive symptom correlation on esophageal functioning tests, presence of esophagitis on endoscopy or typical GERD symptoms sensitive to PPI medication. IEM is classified in line with the updated Chicago classification v3.0 calculating the distal contractile integral (DCI) on high-resolution manometry (HRM) [18]. The DCI represents an index of contractile vigor calculated as the product of amplitude, duration and span of the distal esophageal contraction and should have a range of $450-80000 \mathrm{mmHg} \mathrm{cm} \mathrm{s}$. An ineffective swallow is characterized by a DCI $<450 \mathrm{mmHg} \mathrm{s} \mathrm{cm}$. IEM is diagnosed if $\geq 50 \%$ of 10 swallows is ineffective.

\section{Surgery}

All procedures were performed by the same specialized upper gastrointestinal surgical team. The surgical approach was laparoscopic in all cases. All procedures were standardized regarding surgeon's and patient's positions (antiTrendelenburg), trocar sites and used instruments. These procedures were accomplished by hiatal dissection and crural closure with 1-5 stitches using non-absorbable sutures. Due to the moderate evidence for the use of an esophageal bougie, as well as the associated risks, all cases were performed without a bougie [19-25].

\section{Nissen fundoplication}

LNF was performed in a highly standardized technique as described recently [26]. In brief, both crus of the diaphragm were dissected using the ultrasonic dissector in order to expose the distal esophagus. Special care was taken to achieve an adequate "intraabdominalization" of the lower esophagus of at least $3 \mathrm{~cm}$ in length. An extrashort warp, measuring 1.5 in a maximum with the naked eye was created using 2 close stitches with non-absorbable sutures. Division of the small gastric vessels was avoided when the construction of a tension-free wrap was possible, and special care was taken to complete mobilization of the fundal adhesions to the diaphragm. The first stitch included the anterior esophageal wall. The vagal nerve was always identified and included in the wrap. After the surgery was completed, a blunt laparoscopic instrument was placed through the posterior esophageal wall and the wrap in order to determine the looseness of the fundoplication.

\section{Postoperative care}

Postoperative, all patients undergone LNF received a restricted semiliquid food diet for the first 10 days, slowly progressing to solid food in order to avoid dysphagia during the development of mucosal edema. After at least one overnight stay, patients were discharged from the hospital once they showed an unremarkable contrast swallow with diatrizoate on the first postoperative day.

\section{Postoperative assessment}

The 72 consecutive patients with IEM and 72 patients without IEM who underwent LNF in our specialized center were included in a comparative analysis. They were matched based on age, sex, preoperative BMI, HH size, preoperative total number of reflux episodes, $\mathrm{pH}$ percentage time, presence of Barrett's esophagus (BE) and follow-up time.

The median follow-up time was 5 years. Follow-up was performed by the same physician using a standardized interview assessing postoperative gastrointestinal symptoms, PPI intake and GERD-health-related-quality-of-life (GERD-HRQL). The frequency and severity of postoperative dysphagia were assessed using the classification of Saeed et al. [27], where the ability to swallow can be scored from 0 to 5 , where 0 is inability to swallow and 5 is normal swallowing. Adverse effects such as complications, hospital readmission, emergency surgery or elective reoperation were documented. 


\section{Statistical analysis}

Statistical analysis was performed using SPSS $^{\circledR}$ statistics 20.0 (IBM, Armonk, NY). Data were described using median (interquartile range) or mean (range). Statistical analysis appropriate for nonparametric data was used. Categorical variables were assessed using the Fisher exact test and continuous data using the Wilcoxon rank test as appropriate. Statistical significance was defined as a $p$ value $<0.05$.

This study (2293/2017) was approved by the Institutional Review Board of the Medical University of Vienna, Austria.

\section{Results}

A total of 652 patients underwent LNF for chronic gastroesophageal reflux disease in a period of 16 years in our specialized upper gastrointestinal surgery center. Seventynine $(n=79)$ consecutive patients that presented with IEM according to the Chicago classification v3.0, underwent LNF. Ultimately seven were lost to follow-up, and a total of 72 patients were matched based on sex, age, BMI, $\mathrm{HH}$ size, total $\mathrm{pH}$ percentage time, total number of reflux episodes, presence of BE and follow-up time with 72 patients without IEM.

The three most common preoperative GERD symptoms in patients with IEM were heartburn (88\%), regurgitations $(56 \%)$ and dysphagia (29\%); in contrast to patients with normal motility, heartburn (88\%), regurgitations (56\%) and respiratory symptoms $(19 \%)$. We found a significant difference in the preoperative occurrence of dysphagia in patients between the two groups (29\% IEM vs. $11 \%$ no IEM, $p=0.007$ ) (Table 1).

\section{Outcome}

\section{Operative parameters}

There was no significant difference in the operation time when comparing the two groups (98 min IEM vs. $69 \mathrm{~min}$ no IEM, $p=0.671$ ). No intraoperative complications were seen. All patients received a hiatoplasty, whereas in seven patients (5\%), a hiatal mesh was implanted additionally (Table 2).

\section{Symptom relief}

The median follow-up time was 5 years (IQR, 1.8-10). Heartburn, regurgitations and dysphagia were fully eliminated in ninety-six (76\%), sixty (74\%) and seventeen (59\%) of the patients, respectively, with no significant difference between the two groups. A comparison of the three most reported symptoms before and after LNF is shown in Fig. 1. Eighty-nine (79\%) patients reported to be completely free of PPIs postoperatively, while twenty-four $(21 \%)$ patients needed regular PPI use, with no difference between patients with IEM and those without (11 IEM vs. 13 no IEM, $p=0.655$ ).

\section{Side effects}

Persistent dysphagia was reported in only three (2\%) patients. Rarely difficulties swallowing with solids only was reported by thirty (21\%) of the patients, while ten (7\%)

Table 1 Demographic data and results of preoperative diagnostics of all patients

\begin{tabular}{|c|c|c|c|}
\hline & IEM & No IEM & \\
\hline Total $n=144(100 \%)$ & $N=72(50 \%)$ & $N=72(50 \%)$ & \\
\hline Sex (M vs. F) & 41 versus 31 & 41 versus 31 & $p=1$ \\
\hline Median age (IQR) & 55 & 55 & $p=0.862$ \\
\hline Median BMI (IQR) & 27 & 27 & $p=0.716$ \\
\hline Median size of $\mathrm{HH}(\mathrm{cm})$ & 2 & 2 & $p=0.439$ \\
\hline Median total $\mathrm{pH}<4 \%$ & 9.7 & 7.3 & $p=0.216$ \\
\hline Median total reflux episodes & 78 & 67 & $p=0.562$ \\
\hline Presence of $\mathrm{BE}$ & 8 & 7 & $p=0.554$ \\
\hline Use of PPIs & 56 & 57 & $p=0.839$ \\
\hline Symptoms & 63 & 63 & $p=1$ \\
\hline Heartburn & 41 & 41 & $p=1$ \\
\hline Regurgitations & 21 & 8 & $p=0.07$ \\
\hline Dysphagia & & & \\
\hline
\end{tabular}


patients had occasional difficulties swallowing with solids (Fig. 2). A whole of 112 (57 IEM vs. 55 no IEM, $p=0.688$ ) patients retained their ability to belch/vomit and 15 (6 IEM vs. 9 no IEM, $p=0.413$ ) complained about increased daily gas bloating, with no difference between the groups.

Table 2 Intraoperative and perioperative data

\begin{tabular}{llll}
\hline & IEM & No IEM & \\
\hline Median OR duration (min) & 97.5 & 69 & $p=0.671$ \\
Hiatal repair & 72 & 72 & $p=1$ \\
Median blood loss (ml) & 0 & 0 & - \\
Intraoperative complications & 0 & 0 & - \\
\hline
\end{tabular}

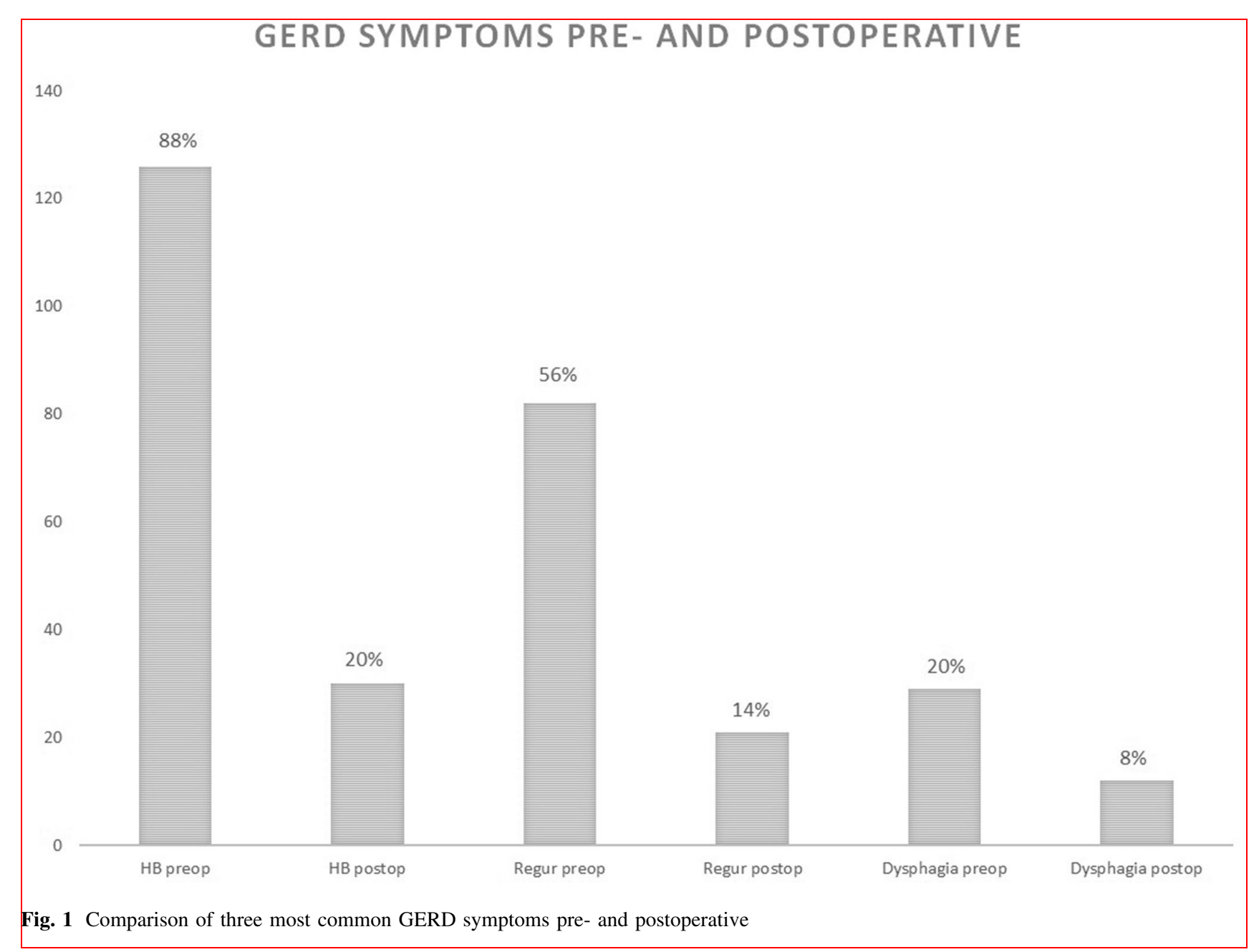

Fig. 1 Comparison of three most common GERD symptoms pre- and postoperative

\section{Dysphagia}

There were a total of twenty-nine (20\%) patients who reported preoperative dysphagia. After LNF, seventeen of the patients $(n=17 / 29,59 \%)$ reported a full elimination of dysphagia, while seven $(n=7 / 29,24 \%)$ patients reported rarely difficulties swallowing with solids, four patients ( $n=4 / 29,14 \%$ ) occasional difficulties swallowing with solids and one patient $(n=1 / 29,3 \%)$ persistent dysphagia (PD). When analyzing new-onset dysphagia, we observed twenty-three patients $(n=23 / 115,20 \%)$ that developed rarely difficulties swallowing with solids, six $(n=6 / 115$, $5 \%$ ) occasional difficulties swallowing with solids and two ( $n=2 / 115,2 \%$ ) PD. From the total of 31 patients with new-onset dysphagia, eleven $(35 \%)$ had preoperative IEM, while the rest twenty patients $(65 \%)$ had no IEM. These findings show there was no increased rate of new-onset dysphagia in patients with preoperative IEM (11 IEM vs. 20 no IEM, $p=0.068)$. There was no significant difference in PD ( 2 IEM vs. 1 no IEM, $p=0.559$ ) between the groups (Table 3). PD was described in one patient where 


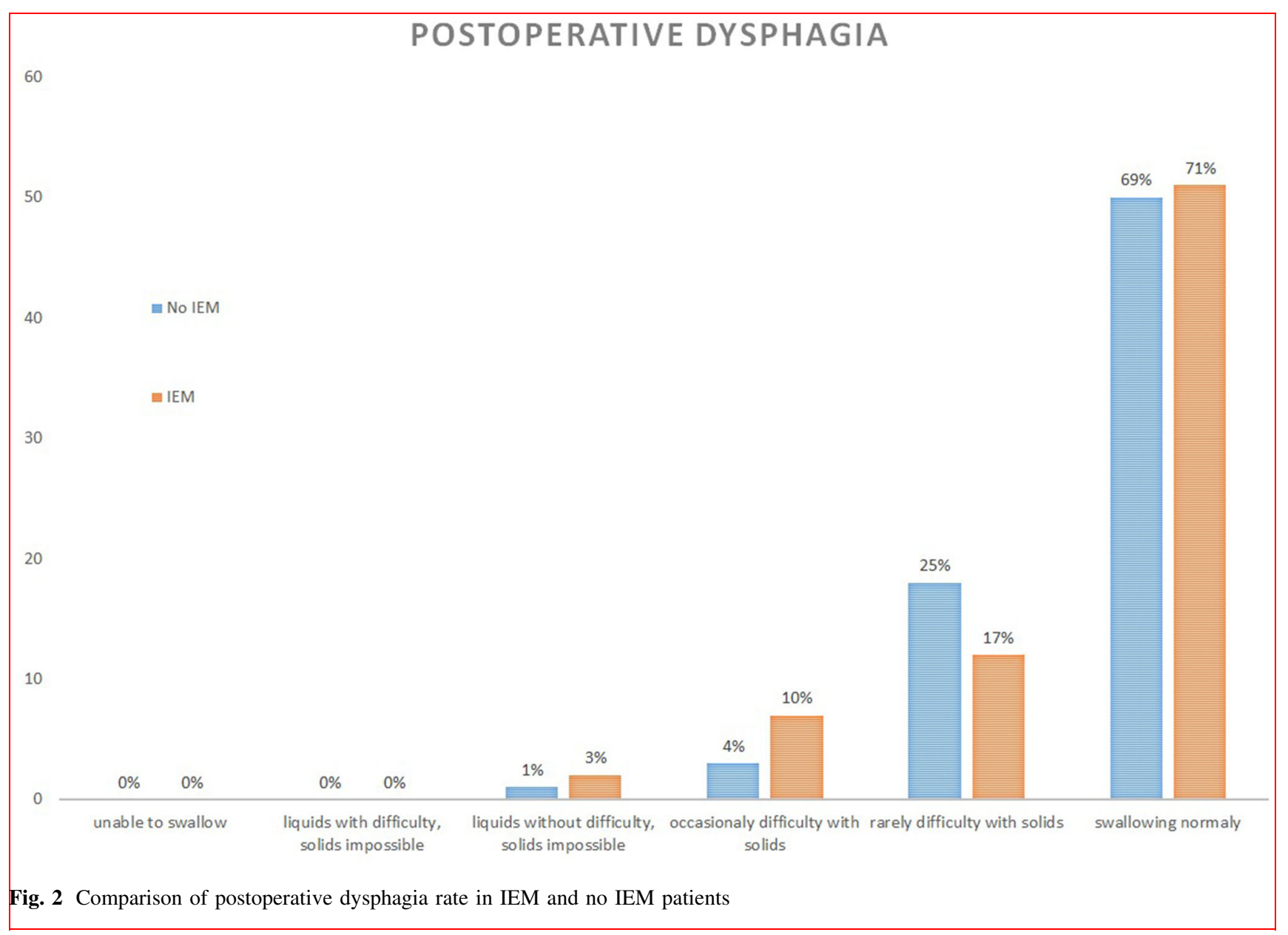

postoperative diagnostics (barium swallow, real-time MRI and EGD) showed no morphologic abnormalities so that no re-operation was indicated, but multiple Botox injections. Two further patients with PD also showed no abnormalities in the postoperative barium swallow, real-time MRI or even EGD, and no further interventions were done.

Table 3 Postoperative median follow-up of 5 years

\begin{tabular}{lccl}
\hline & IEM & No IEM & \\
\hline New-onset dysphagia & 11 & 20 & $p=0.068$ \\
Persistent dysphagia $^{\text {a }}$ & 2 & 1 & $p=0.559$ \\
Ability to belch/vomit & 57 & 55 & $p=0.688$ \\
Daily gas bloating & 6 & 9 & $p=0.413$ \\
Revision surgery & 6 & 2 & $p=0.145$ \\
Median GERD-HRQL score & 2 & 1 & $p=0.055$ \\
Alimentary satisfaction & 9 & 10 & $p=0.3$ \\
\hline
\end{tabular}

${ }^{\text {a Persistent dysphagia was defined as } \leq 2 \text { using the classification of }}$ Saeed et al. [20]

\section{Interventions}

Endoscopic dilatation was performed in three patients (2\%) with postoperative dysphagia, with one of them having a successful outcome (33\%). Multiple endoscopic Botox injections were performed in one patient (1.4\%) with postoperative dysphagia with no significant resolution. Eight patients $(6 \%)$ required re-operation. Three (38\%) patients due to re-herniation of the wrap: one patient suffered an acute paraesophageal hernia on the 2 postoperative day, one patient developed a re-herniation 6 months after the primary surgery and one patient needed open revision due to occurrence of a type IV hiatal hernia 4 years later. Two patients (25\%) due to slipping of the fundus, 6 months and 4 years after the primary surgery, respectively. Two further patients $(25 \%)$ due to reoccurrence of reflux as well as slipping of the fundus. One of them 10 years after the primary surgery and the other 5 years later, after which he developed dysphagia undergoing multiple endoscopic balloon dilatations, followed by three stent implantations, finally resolving his dysphagia. Lastly, one patient underwent Toupet re-fundoplication due to dysphagia 3 years 
later $(13 \%)$. We found no difference in the rates of reoperation between the two groups (6 IEM vs. 2 no IEM, $p=0.145)($ Table 3$)$.

\section{Quality of life}

The preoperative median GERD-HRQL was 19 (IQR, 14-24). LNF led to a significant reduction in the GERDHRQL total score (19 (IQR, 14-24) vs. 2 (IQR, 0-5), $p=0.00$ ). No difference was found in the postoperative GERD-HRQL score (2 IEM vs. 1 no IEM, $p=0.055$ ) or the median alimentary satisfaction (9 IEM vs. 10 no IEM, $p=0.3$ ) between the groups (Table 3 ).

\section{Discussion}

Despite the hypothesis that patients with coexisting IEM may have a greater risk for postoperative dysphagia, it still remains controversial if they would benefit more from a partial fundoplication or if esophageal motility itself has an influence on postoperative outcome at all $[8,10,12-15,28,29]$. Moreover, esophageal motility has shown to improve after LNF either through mucosal healing with reflux control or increased outflow resistance by augmenting the gastroesophageal junction [17]. As LNF remains superior to partial fundoplication in long-term reflux control, the tailored anti-reflux concept in IEM patients' should be reconsidered.

In our study we aimed to compare long-term postoperative outcomes after LNF between patients with preoperative IEM and those with regular motility. Up to date, no study has been published with a long-term follow-up of up to 14 years and a greater case-matched sample size of patients with IEM based on the Chicago classification v3.0 and diagnosed with HRM.

When analyzing the preoperative GERD presentations - the three most common symptoms differed between the groups. Patients with IEM presented with heartburn (79\%), regurgitations (61\%) and dysphagia (33\%), in contrast to patients with normal motility who presented more commonly with respiratory symptoms (16\%), rather than dysphagia. The significant difference in preoperative dysphagia rates between the groups (33\% IEM vs. $15 \%$ no IEM, $p=0.06$ ) is not surprising, supporting previous evidence that esophageal motility influences symptoms of the disease [13]. This may be one of the reasons why the choice of fundoplication is occasionally still made according to the presence of IEM. Furthermore, when comparing the elimination of the symptoms, preoperative esophageal motility had no effect on the postoperative rates of heartburn (18 IEM vs. 12 no IEM, $p=0.218$ ), regurgitations (13 IEM vs. 8 no IEM, $p=0.266$ ), dysphagia ( 2
IEM vs. 1 no IEM, $p=0.559$ ) or postoperative PPI use (11 IEM vs. 13 no IEM, $p=0.655)$. These findings are coinciding with foregoing data that IEM has no influence on postoperative outcome after $\operatorname{LNF}[12,13,15,30]$.

The opinion that patients with preoperative IEM have an increased risk of postoperative dysphagia led to recommendations for tailoring or even avoiding anti-reflux surgery in these patients. In order to reduce the perceived likelihood of this feared side effect, many prefer the Toupet over the Nissen fundoplication, even though to date no prospective data exist to encourage such practice [30-33]. In our study, we observed a total of three patients with PD with solids and liquids (2\%) at time of follow-up. This is in concordance with our prior findings when analyzing 350 patients after LNF at our institution and considerably lower than described in the previous literature ranging from 4 to $11 \%$ [26, 34, 35]. Moreover, as mentioned above, when comparing patients with IEM and those without IEM, we found no significant difference in the postoperative PD rate ( 2 IEM vs. 1 no IEM, $p=0.559$ ) or in the rate of new-onset dysphagia (11 IEM vs. 20 no IEM, $p=0.068$ ), confirming the results of the previous literature showing that esophageal motility has no effect on the postoperative occurrence of dysphagia after fundoplication [12, 13, 15]. Furthermore, these findings show that when performed in a specialized high-output reflux center, in a highly standardized technique, the long-term postoperative dysphagia rates after LNF are low. Additionally, the elimination of pathological reflux and restoration of the anatomy possibly results in improvement of esophageal motility, and thus dysphagia itself. When analyzing further possible adverse effects of the LNF such as gas bloat syndrome (6 IEM vs. 9 no IEM, $p=0.413$ ) and the inability to belch and/or vomit (57 IEM vs. 55 no IEM, $p=0.688$ ), no difference was observed in the outcome between the groups, in concordance with earlier evidence [13].

In the small subset of patients that do develop side effects like persistent dysphagia or recurrence of GERD symptoms, interventions like endoscopic balloon-dilatation or revision fundoplication are still possible treatment options. In our series, we had three patients who underwent endoscopic dilatation due to dysphagia, on the lower end when compared to several studies [36, 37]. Eight patients underwent revision surgery, mostly due to re-herniation of the wrap as well as GERD reoccurrence and slipping of the fundus with no difference between the two groups (6 IEM vs. 2 no IEM, $p=0.145$ ). These finding were not unpredicted as the incidence of $2-6 \%$ has been commonly described, increasing with the time of follow-up [13, 15].

Lastly, our results showed a significant decrease in the GERD-HRQL total score (19 (IQR, 14-24) vs. 2 (IQR, $0-5), p=0.00$ ) after LNF, proving a substantial increase in quality of life and confirming previous outcomes [38, 39]. 
Certain limitations of our study, like its retrospective nature, as well as a lack of objective (EFTs) postoperative assessment of GERD and preoperative dysphagia elimination should be taken into consideration. A prospective randomized clinical trial is currently being initiated in order to bring evidence to a higher level and resolve the contraversion about tailoring LNF in patients with IEM.

\section{Conclusion}

Our findings showed that although IEM diagnosed in preoperative HRM affects the clinical symptoms of GERD, it does not affect the outcome of LNF. LNF is a safe and effective surgical procedure with low postoperative morbidity rates and efficient symptom relief not only in patients with normal esophageal motility but also in those with IEM.

Acknowledgements Open access funding provided by Medical University of Vienna.

Open Access This article is distributed under the terms of the Creative Commons Attribution 4.0 International License (http://crea tivecommons.org/licenses/by/4.0/), which permits unrestricted use, distribution, and reproduction in any medium, provided you give appropriate credit to the original author(s) and the source, provide a link to the Creative Commons license, and indicate if changes were made.

Authors' contribution All authors listed above contributed substantially to the conception or design of the work and the acquisition, analysis or interpretation of data for the work; and all authors contributed to the drafting of the work or revising it critically for important intellectual content and the final approval of the version to be published; and all authors agree to be accountable for all aspects of the work in ensuring that questions related to the accuracy or integrity of any part of the work are appropriately investigated and resolved.

Funding No financial support or other assistance received for this study.

\section{References}

1. El-Serag HB, Sweet S, Winchester CC, Dent J (2014) Update on the epidemiology of gastro-oesophageal reflux disease: a systematic review. Gut 63(6):871-880

2. Gyawali CP, Fass R (2018) Management of gastroesophageal reflux disease. Gastroenterology 154(2):302-318

3. Khan F, Maradey-Romero C, Ganocy S, Frazier R, Fass R (2016) Utilisation of surgical fundoplication for patients with gastrooesophageal reflux disease in the USA has declined rapidly between 2009 and 2013. Aliment Pharmacol Ther 43(11):1124-1131

4. Neuvonen P, Sand J, Matikainen M, Rantanen T (2017) Does Nissen fundoplication provide lifelong reflux control? Symptomatic outcome after 31-33 years. World J Surg 41(8):2046-2052. https://doi.org/10.1007/s00268-017-3924-8
5. Blom D, Peters JH, DeMeester TR, Crookes PF, Hagan JA, DeMeester SR, Bremner C (2002) Physiologic mechanism and preoperative prediction of new-onset dysphagia after laparoscopic Nissen fundoplication. J Gastrointest Surg 6(1):22-27 (discussion 27-28)

6. Reynolds JL, Zehetner J, Wu P, Shah S, Bildzukewicz N, Lipham JC (2015) Laparoscopic magnetic sphincter augmentation vs laparoscopic Nissen fundoplication: a matched-pair analysis of 100 patients. J Am Coll Surg 221(1):123-128

7. Moore M, Afaneh C, Benhuri D, Antonacci C, Abelson J, Zarnegar R (2016) Gastroesophageal reflux disease: a review of surgical decision making. World J Gastrointest Surg 8(1):77-83

8. Wang B, Zhang W, Liu S, Du Z, Shan C, Qiu M (2015) A Chinese randomized prospective trial of floppy Nissen and Toupet fundoplication for gastroesophageal disease. Int J Surg 23(Pt A):35-40

9. Stylopoulos N, Rattner DW (2005) The history of hiatal hernia surgery: from Bowditch to laparoscopy. Ann Surg 241(1):185-193

10. Schwameis K, Zehetner J, Rona K, Crookes P, Bildzukewicz N, Oh DS, Ro G, Ross K, Sandhu K, Katkhouda N et al (2017) Post-Nissen dysphagia and bloating syndrome: outcomes after conversion to Toupet fundoplication. J Gastrointest Surg 21(3):441-445

11. Kapadia S, Osler T, Lee A, Borrazzo E (2018) The role of preoperative high resolution manometry in predicting dysphagia after laparoscopic Nissen fundoplication. Surg Endosc 32(5):2365-2372

12. Booth MI, Stratford J, Jones L, Dehn TC (2008) Randomized clinical trial of laparoscopic total (Nissen) versus posterior partial (Toupet) fundoplication for gastro-oesophageal reflux disease based on preoperative oesophageal manometry. Br J Surg 95(1):57-63

13. Strate U, Emmermann A, Fibbe C, Layer P, Zornig C (2008) Laparoscopic fundoplication: Nissen versus Toupet two-year outcome of a prospective randomized study of 200 patients regarding preoperative esophageal motility. Surg Endosc 22(1):21-30

14. Jobe BA, Wallace J, Hansen PD, Swanstrom LL (1997) Evaluation of laparoscopic Toupet fundoplication as a primary repair for all patients with medically resistant gastroesophageal reflux. Surg Endosc 11(11):1080-1083

15. Patti MG, Robinson T, Galvani C, Gorodner MV, Fisichella PM, Way LW (2004) Total fundoplication is superior to partial fundoplication even when esophageal peristalsis is weak. J Am Coll Surg 198(6):863-869

16. Simic AP, Skrobic OM, Gurski RR, Sljukic VM, Ivanovic NR, Pesko PM (2014) Can different subsets of ineffective esophageal motility influence the outcome of Nissen fundoplication? J Gastrointest Surg 18(10):1723-1729

17. Herbella FA, Tedesco P, Nipomnick I, Fisichella PM, Patti MG (2007) Effect of partial and total laparoscopic fundoplication on esophageal body motility. Surg Endosc 21(2):285-288

18. Kahrilas PJ, Bredenoord AJ, Fox M, Gyawali CP, Roman S, Smout AJ, Pandolfino JE (2015) International high resolution manometry working G: the Chicago classification of esophageal motility disorders, v3.0. Neurogastroenterol Motil 27(2):160-174

19. Patterson EJ, Herron DM, Hansen PD, Ramzi N, Standage BA, Swanstrom LL (2000) Effect of an esophageal bougie on the incidence of dysphagia following Nissen fundoplication: a prospective, blinded, randomized clinical trial. Arch Surg 135(9):1055-1061 (discussion 1061-1052)

20. Somasekar K, Morris-Stiff G, Al-Madfai H, Barton K, Hassn A (2010) Is a bougie required for the performance of the fundal wrap during laparoscopic Nissen fundoplication? Surg Endosc 24(2):390-394

21. Zacharoulis D, O'Boyle CJ, Sedman PC, Brough WA, Royston CM (2006) Laparoscopic fundoplication: a 10-year learning curve. Surg Endosc 20(11):1662-1670 
22. Lowham AS, Filipi CJ, Hinder RA, Swanstrom LL, Stalter K, dePaula A, Hunter JG, Buglewicz TG, Haake K (1996) Mechanisms and avoidance of esophageal perforation by anesthesia personnel during laparoscopic foregut surgery. Surg Endosc 10(10):979-982

23. DeMeester TR, Bonavina L, Albertucci M (1986) Nissen fundoplication for gastroesophageal reflux disease. Evaluation of primary repair in 100 consecutive patients. Ann Surg 204(1):9-20

24. Ng A, Yong D, Hazebroek E, Berry H, Radajewski R, Leibman S, Smith GS (2009) Omission of the calibration bougie in laparoscopic repair of paraesophageal hernia. Surg Endosc 23(11):2505-2508

25. Walsh JD, Landercasper J, Boyd WC, Lambert PJ, Havlik PJ (2003) Patient outcomes and dysphagia after laparoscopic antireflux surgery performed without use of intraoperative esophageal dilators. Am Surg 69(3):219-223

26. Nikolic M, Schwameis K, Semmler G, Asari R, Semmler L, Steindl A, Mosleh BO, Schoppmann SF (2018) Persistent dysphagia is a rare problem after laparoscopic Nissen fundoplication. Surg Endosc 33(4):1196-1205

27. Saeed ZA, Winchester CB, Ferro PS, Michaletz PA, Schwartz JT, Graham DY (1995) Prospective randomized comparison of polyvinyl bougies and through-the-scope balloons for dilation of peptic strictures of the esophagus. Gastrointest Endosc 41(3):189-195

28. El-Hak NA, Zeid MA, Aboelemen A, Fouad A, Abd Alla T, El Shoubary M, Kandel T, Hamdy E, Abdel Wahab M, Fathy O et al (2005) Partial posterior wrap (Toupet) in patients with defective esophageal body motility. Saudi J Gastroenterol 11(2):73-84

29. Granderath FA, Kamolz T, Schweiger UM, Pasiut M, Wykypiel H Jr, Pointner R (2002) Quality of life and symptomatic outcome three to five years after laparoscopic Toupet fundoplication in gastroesophageal reflux disease patients with impaired esophageal motility. Am J Surg 183(2):110-116

30. Fibbe C, Layer P, Keller J, Strate U, Emmermann A, Zornig C (2001) Esophageal motility in reflux disease before and after fundoplication: a prospective, randomized, clinical, and manometric study. Gastroenterology 121(1):5-14
31. Patti MG, Arcerito M, Pellegrini CA, Mulvihill SJ, Tong J, Way LW (1995) Minimally invasive surgery for gastroesophageal reflux disease. Am J Surg 170(6):614-617 (discussion 617-618)

32. Waring JP, Hunter JG, Oddsdottir M, Wo J, Katz E (1995) The preoperative evaluation of patients considered for laparoscopic antireflux surgery. Am J Gastroenterol 90(1):35-38

33. Kauer WK, Peters JH, DeMeester TR, Heimbucher J, Ireland AP, Bremner CG (1995) A tailored approach to antireflux surgery. J Thorac Cardiovasc Surg 110(1):141-146 (discussion 146-147)

34. Schietroma M, Piccione F, Clementi M, Cecilia EM, Sista F, Pessia B, Carlei F, Guadagni S, Amicucci G (2017) Short- and long-term, 11-22 years, results after laparoscopic Nissen fundoplication in obese versus nonobese patients. J Obes 2017:7589408

35. Galmiche JP, Hatlebakk J, Attwood S, Ell C, Fiocca R, Eklund S, Langstrom G, Lind T, Lundell L, Collaborators LT (2011) Laparoscopic antireflux surgery vs esomeprazole treatment for chronic GERD: the LOTUS randomized clinical trial. JAMA 305(19):1969-1977

36. Lafullarde T, Watson DI, Jamieson GG, Myers JC, Game PA, Devitt PG (2001) Laparoscopic Nissen fundoplication: five-year results and beyond. Arch Surg 136(2):180-184

37. Schietroma M, De Vita F, Carlei F, Leardi S, Pessia B, Sista F, Amicucci G (2013) Laparoscopic floppy Nissen fundoplication: 11-year follow-up. Surg Laparosc Endosc Percutaneous Tech 23(3):281-285

38. Granderath FA, Kamolz T, Schweiger UM, Pointner R (2002) Long-term follow-up after laparoscopic refundoplication for failed antireflux surgery: quality of life, symptomatic outcome, and patient satisfaction. J Gastrointest Surg 6(6):812-818

39. Kobiela J, Kaska L, Pindel M, Szarmach A, Janiak M, ProczkoMarkuszewska M, Stefaniak T, Laski D, Lachinski A, Sledzinski Z (2015) Dynamics of quality of life improvement after floppy Nissen fundoplication for gastroesophageal reflux disease. Wideochir Inne Tech Maloinwazyjne 10(3):389-397

Publisher's Note Springer Nature remains neutral with regard to jurisdictional claims in published maps and institutional affiliations. 